\title{
Evaluation of Cementitious Repair Mortars for Corrosion Resistance
}

\author{
V. Saraswathy ${ }^{a, *}$ and Ha-Won Song ${ }^{b}$ \\ a) Corrosion Protection Division, Central Electrochemical Research Institute, Karaikudi, \\ Tamil Nadu, India \\ ${ }^{b)}$ School of Civil and Environmental Engineering, Yonsei University, \\ Seoul 120-749, Republic of Korea
}

Received 13 February 2008; accepted 6 June 2008

\begin{abstract}
Repair and rehabilitation of deteriorated concrete structures are essential not only to utilize them for their intended service life, but also to assure the safety and serviceability of the associated components. A good repair improves the function and performance of the structure, thus prevents ingress of aggressive species to the steel/concrete interface and improves its durability. It is important to evaluate the performance of repair materials available for repairing the deteriorated concrete structures. This investigation was carried out to evaluate the durability characteristics of five types of modified cement based repair mortars. The corrosion resistance of the repair materials was evaluated by conducting various tests such as water absorption, rapid chloride ion penetration test, impressed voltage, 90 days ponding test, macro cell corrosion test, weight loss measurement, etc. Details of the test and their results were discussed. It is concluded that the modified cement based repair mortars formulated with different mineral admixtures (fly ash and/or silica fume) showed improved corrosion resistance.
\end{abstract}

Keywords: concrete, corrosion, steel.

\section{Introduction}

Hydrated cement is a porous solid, which usually provides good protection against corrosion of reinforced steel bars but, nevertheless, corrosion remains the most common cause of deterioration. In the alkaline pore solution in set cement ( $\mathrm{pH}$ 12.5-13.5), a protective oxide film is formed over the steel, rendering it passive [1-3].

\footnotetext{
* Corresponding author. E-mail address: corrsaras@yahoo.com
} 
Corrosion of the reinforced concrete structures occurs when the protective oxide film is destroyed by carbonation or by penetration of aggressive ions such as chloride ion to the steel surface [2, 4 and 5]. In sea water, the penetration of chloride ions is faster than that of $\mathrm{CO}_{2}$ and makes the $\mathrm{CO}_{2}$ influence weaker [6]. The presence of chloride ions raises the $\mathrm{pH}$ required to stabilize the passive film to a value which may exceed that of a saturated calcium hydroxide solution, so stimulating corrosion [1]. Between the two principal factors that characterize the deterioration process of concrete structures due to chloride corrosion, the diffusion of chloride ions dominates the generation of corrosion, while the diffusion of oxygen dominates its rate [7]. Carbonation, being a rather slow process, induces rebar corrosion only in concrete structures with very thin concrete cover and high porosity, shrinkage cracks and so forth [8]. The steel rebars corrosion onset, the time interval before the attack starts and the rate by which it proceeds, are dependent on factors influenced by the chemistry of cement, mineral admixture additions and water to binder ratio, curing and environmental conditions [4, 6, 9-11].

The durability of a material or structure refers to its ability to withstand the environmental conditions to which it is exposed. Although concrete structures have mostly performed satisfactorily during their service life, there are nevertheless significant problems which occur in many structures and the causes are often related to the durability of the composite material. As a result, in recent years repair, refurbishment and maintenance of concrete structures have become a significant part of the total cost of construction world wide [12]. For this reason, it is very important to select a suitable repair material for corrosion resistance. As it is well known, there are a wide range of cementitious repair mortars based on cement and components similar to those of concrete. The composition of repair mortars could sometime consist of more than one type of cement (i.e. special cement, like ultra-fine alumina cement) together with additions (i.e. silica fume, slag or fly ash), aggregates (normal, lightweight and special types, fillers), admixtures, such as plasticizers, air entrainers and accelerators, polymer additives and fine polymer fibers [13-16].

Water based polymer systems are often used for improvement in the properties of plain cement mortar or concrete. Presently, latexes of a single or combinations of polymers like polyvinyl acetate, copolymers of vinyl acetate-ethylene, styrenebutadiene, styrene-acrylic, and acrylic and styrene butadiene rubber emulsions are generally used. One of the limitations of these polymer systems is that they may re-emulsify in humid alkaline conditions. Aggarwal et al. [17] studied the properties of polymer-modified mortars using epoxy and acrylic emulsions and found that the mortars with the newly developed system have superior strength properties and better resistance to the penetration of chloride ions and carbon dioxide. It has also been reported that, polymeric based cement mortars and concrete have been used in repairing damaged concrete structures. These kinds of products, besides restoring the alkaline medium, have also other complementary properties according to the manufacturers: compensated shrinkage, high bond to concrete mass, low permeability and high strength [18]. 
Self-compacting repair mortars (SCRM) is a new technology preferred for the rehabilitation and repair of reinforced concrete structures. The selfcompactability of repair mortars may bring considerable advantages at narrow mould systems. However, due to the high powder content and absence of coarse aggregate, plain SCRMs are susceptible to surface abrasion, especially in case of repair of surfaces under high rates of abrasion. It was reported that the steel fiber reinforcement can be an excellent solution for the abrasion resistance problem of SCRMs [19].

The resin-based products are also used as repair materials, but these are very expensive, compared to cement based ones. Considering the cost and behaviour of resin-based materials, the use of modified cementitious materials has been on the increase in developing countries. In addition to low cost, it provides the highly alkaline environment required to re-passivate the steel reinforcement. This cement based repair materials are prepared by ordinary Portland cement river sand, fly ash, silica fume, micro silica and super plasticizer. This type of repair materials can prove to be excellent ones, because they provide greater compressive, tensile and flexural strength properties. Their dense surfaces, which often have very low permeability, make them extremely suitable to resist to aggressive chemical exposure (or) the ingress of moisture. In the present investigation five types of repair mortars were formulated and evaluated for their corrosion resistance using various electrochemical tests.

\section{Experimental detail}

\section{Materials used for this study}

- Ordinary Portland cement of 43 grade as per IS 8112.

- River sand passing through $2.36 \mathrm{~mm}$ sieve.

- $\mathrm{NaCl}-1 \%$ by weight of cement.

- Demonized water was used for the investigation.

- MS - micro silica supplied by the Elkem is used for the investigation.

- SP - super plasticizer (added by weight of cement) supplied by Apple Chemie is used for the investigation.

- UFA - untreated fly ash (fly ash passing through 90 micron sieve).

- TFA - fly ash is treated with specific percentage of $1 \%$ calcium oxide and $1 \%$ sodium silicate at $100{ }^{\circ} \mathrm{C}$ for an hour. Chemical activation is effected by alkali activation followed by addition of $\mathrm{CaO}$. This process enhanced the $\mathrm{OH}^{-}$ concentration and thereby obviously showing higher $\mathrm{pH}$ values than that of $\mathrm{Ca}(\mathrm{OH})_{2}$ saturated liquid, thus greatly facilitating silica-alumina glassy chain corrosion.

- Fly ash and micro silica are replaced by weight of cement.

- The physical properties, such as specific gravity and specific surface area of fly ash used are $2.31 \mathrm{~g} / \mathrm{cm}^{3}$ and $386 \mathrm{~m}^{2} / \mathrm{kg}$, respectively.

- The chemical composition of cement and fly ash used is given in Table 1. 
Table 1. Composition of OPC and fly ash (FA) used in this study.

\begin{tabular}{|c|c|c|}
\hline Constituents & OPC (\%) & FA (\%) \\
\hline $\mathrm{SiO}_{2}$ & 22.14 & 64.03 \\
\hline $\mathrm{Fe}_{2} \mathrm{O}_{3}$ & 3.35 & 6.50 \\
\hline $\mathrm{Al}_{2} \mathrm{O}_{3}$ & 9.93 & 15.50 \\
\hline $\mathrm{CaO}$ & 60.68 & 4.62 \\
\hline $\mathrm{MgO}$ & 1.30 & 3.00 \\
\hline Loss on ignition & 2.60 & 4.35 \\
\hline Insoluble residue & --- & 2.00 \\
\hline
\end{tabular}

Mortars (1:3) formulated and used for this study are:

- System I - OPC + SAND + 5\% TFA + 1.5\% SP; w/c $=0.42$

- System II - OPC + SAND + 5\% TFA + 5\% MS + 1.5\% SP; w/c $=0.42$

- System III - OPC + SAND + 7\% TFA + 1.5\% SP; w/c $=0.42$

- System IV - OPC + SAND + 5\% UFA + 5\% MS + 1.5\% SP; w/c $=0.42$

- System V - OPC + SAND + 7\% UFA + 1.5\% SP; w/c $=0.42$

The tests carried out for this study are: test for density, permeable voids and water absorption; open circuit potential measurements; impressed voltage test; rapid chloride ion permeability test (RCPT); 90 days ponding test; macro cell corrosion test; weight loss measurements.

\section{Durability characteristics}

\section{Volume of permeable voids and water absorption coefficient}

The permeability of concrete is a measure of the rate at which a liquid will pass through it. The permeability of concrete depends upon its pore network, which arises from the excess water used during mixing initial hardening process. The overall porosity includes closed or logged pores in addition to a network of inter connected pores. Pore size ranges from a few angstroms to about $100 \mathrm{~A}^{\circ}$ for the so called 'gel pores', from 100 to $100000 \mathrm{~A}^{\circ}$ in 'capillary pores', and a few millimeters in 'air or large pores'. Inter connected pores endow the concrete permeability. All the hydrated cement products are subjected to attack by sulphates, chlorides and acids, and less by water. This is because of low equilibrium solubility of the hydrated components and low mass transfer of wellcured concrete. It is a usual practice to assess the water permeability characteristics when assessing the durability characteristics. Permeability can be measured by conducting standard test methods. In the present investigation, $\%$ of water absorption, $\%$ of permeable voids and $\%$ of total voids have been determined as per ASTM C 642-97.

This test was done as per procedure given in ASTM C 642-97 by oven-drying method. For this test $50 \mathrm{~mm}$ diameter $84 \mathrm{~mm}$ height cylinders were cast. After 24 hours the specimens were demoulded and kept immersed in water for 28 days. At the end of 28 days, the specimens were taken out and air-dried to remove the 
surface moisture. Then, the specimens were dried in an oven at a temperature of $100 \pm 10{ }^{\circ} \mathrm{C}$ for $48 \mathrm{hrs}$, and allowed to cool at room temperature. At the end of 48 hrs, the weights of the specimens were measured to an accuracy of 1 gram using a standard weighing balance. Then the specimens were kept immersed in water continuously for $48 \mathrm{hrs}$.

Initially up to $30 \mathrm{~min}, 1 \mathrm{hr}, 2,3,4,6,24$ and $48 \mathrm{hrs}$, the increase in weight was measured after wiping out the surface water using dry cloth. After $48 \mathrm{hrs}$ of immersion in water the specimens were heated continuously for a period of $5 \mathrm{hrs}$. Then the weights of the specimens were taken after a time gap of $14 \mathrm{hrs}$. The specimens were suspended in water and their submerged weight was determined. To determine the $\%$ of total voids, the apparent specific gravity of the specimen has to be determined. For this, the specimens were broken, crushed and powdered. 64 grams of powdered sample were taken after sieved through $90 \mu$ sieve. Using Lee-Chatlier flask 31, the specific gravity of the powdered sample was determined. From the above data, $\%$ of water absorption, $\%$ of permeable voids, $\%$ of total voids, and water absorption coefficient, were determined by adopting the following procedure:

\section{1. \% of water absorption}

$\%$ of water absorption $\quad=[(\mathrm{B}-\mathrm{A}) / \mathrm{A}] \times 100$

where, $A=$ weight of oven dried sample in air, and $B=$ weight of surface dry sample in air after immersion in water.

2. \% of permeability

Volume of permeable voids $=[(\mathrm{C}-\mathrm{A}) /(\mathrm{C}-\mathrm{D})] \times 100$

where, $\mathrm{C}=$ weight, after $5 \mathrm{hrs}$ heated, and $\mathrm{D}=$ submerged weight in water.

3. $\%$ of total voids

$\%$ of total voids $=\left[\left(\mathrm{g}_{1}-\mathrm{g}_{3}\right) / \mathrm{g}_{3}\right] \times 100$

where, $\mathrm{g}_{1}=\mathrm{A} /(\mathrm{C}-\mathrm{D})$, and $\mathrm{g}_{3}=$ apparent specific gravity of the specimens.

4. Water absorption coefficient

This is measured by the rate of uptake of water or capillary of water by dry concrete for a period of 60 minutes and is computed as follows:

water absorption coefficient $\left(\mathrm{K}_{\mathrm{a}}\right)=[\mathrm{Q} / \mathrm{A}]^{2} \times 1 / \mathrm{t}$

where, $\mathrm{Q}=$ quantity of water absorbed by the oven dry specimen in time $\mathrm{t}$, $\mathrm{A}=$ total surface area of concrete specimen through which water penetrates, and $\mathrm{t}=60$ minutes.

\section{Open circuit potential measurements}

Half portion of the concrete cylinders was cast using M20 concrete and kept immersed in water for 28 days. After 28 days the specimens were taken out and the surface was dried and sand blasted in order to get a rough surface for proper bonding between old and new concrete. Cement slurry was applied over the rough surface and the remaining portion of the cylinder was filled with different repair mortars. During casting $12 \mathrm{~mm}$ diameter and $100 \mathrm{~mm}$ long rebar was centrally embedded in the cylinder specimen of size $50 \mathrm{~mm}$ diameter and 100 $\mathrm{mm}$ height. From one end electrical connection was taken out for potential measurements. The rebars were cleaned with pickling acid before embedding in 
concrete. After casting the specimens were subjected to water curing for 28 days. After the curing period, the cubes were taken out and dried for 24 hours and subjected to alternate wetting and drying in $3 \% \mathrm{NaCl}$ solution. One cycle consists of three days immersion in $3 \% \mathrm{NaCl}$ solution and three days drying in open atmosphere. Open circuit potential measurements were monitored periodically with time under wet condition. The process is continued for 90 days. From the above results potential vs. time plot is drawn using the average potentials obtained.

\section{Impressed voltage test}

The same procedure as mentioned above was adopted for this experiment. During casting $12 \mathrm{~mm}$ diameter and $100 \mathrm{~mm}$ long rebar was centrally embedded in the cylinder specimen of size $50 \mathrm{~mm}$ diameter and $100 \mathrm{~mm}$ height. After $24 \mathrm{hrs}$ of demoulding all the specimens were subjected to 7, 14, 21, 28 and 90 days of curing. After the specified curing period, the specimens were subjected to impressed voltage test by impressing $12 \mathrm{~V}$ between rebar anode and stainless steel cathode in $5 \% \mathrm{NaCl}$ solution. The time taken for an initial crack was recorded for different systems.

\section{Rapid chloride ion permeability test}

Mortar discs of size $85 \mathrm{~mm}$ diameter and $50 \mathrm{~mm}$ thick were cast and allowed to cure for 28 and 90 days. After curing the mortar specimens were subjected to RCPT test by impressing $60 \mathrm{~V}$ as per ASTM C1202. Two halves of the PVC container of diameter $90 \mathrm{~mm}$ and $100 \mathrm{~mm}$ long are fixed on both sides of the concrete specimen. One side of the container is filled with $3 \% \mathrm{NaCl}$ solution (connected to the negative terminal of the power supply) and the other side is filled with $0.3 \mathrm{~N} \mathrm{NaOH}$ solution (connected to the positive terminal of the power supply). Current is measured at every 30 minutes up to $6 \mathrm{hrs}$. Chloride contamination and temperature were also monitored at every 30 minutes. Chloride concentration was determined by Mohr's method [20]. From the results using current and time, chloride permeability is calculated in terms of coulombs at the end of 6 hrs.

\section{0 days ponding test}

Mortar prisms of size $300 \times 150 \times 150 \mathrm{~mm}$ were cast with different repair mortars. These prisms were allowed to cure for 28 days. After 28 days of curing $3 \% \mathrm{NaCl}$ solution is ponded over the upper side of the prism. These prisms are allowed to continuous ponding in $3 \% \mathrm{NaCl}$ up to 90 days. At the end of 90 days core samples were taken at $20 \mathrm{~mm}$ and $40 \mathrm{~mm}$ depth and analyzed for free chloride contamination. The chloride contamination is correlated with the permeability.

\section{Macro cell corrosion studies}

ASTM has evolved a standard for macro cell corrosion studies to evaluate the chemical admixtures in chloride-contaminated concrete (ASTM G109- 2001). 
Half portion of the prism is cast with two-cathode CTD rebars of $12 \mathrm{~mm}$ diameter $300 \mathrm{~mm}$ length using M20 concrete, as shown in Fig. 1. After 24 hours the half portion of the prism is demoulded and subjected to curing in water for 28 days. After 28 days the specimens were taken out and the surface was roughened using the sand blasting technique. Then the roughened surface is coated with cement slurry and the repair mortar is applied over the remaining portion with one $16 \mathrm{~mm}$ rebar at the top kept at the center of the mortar specimen at a cover of $20 \mathrm{~mm}$ from the top portion. After the application of the repair mortar the whole specimen is immersed in water for 7 days. After 7 days the prisms were taken out and the top portion was constructed with bund for ponding of $3 \% \mathrm{NaCl}$ solution. During exposure to salt solution, chloride ions tend to diffuse into the cover mortar and depassivate the steel positioned at the top level. The top $250 \mathrm{~mm}$ length bar will act as an anode while bottom rebars will act as a cathode. To accelerate galvanic corrosion, the area ratio of anode: cathode was kept as 1:2.

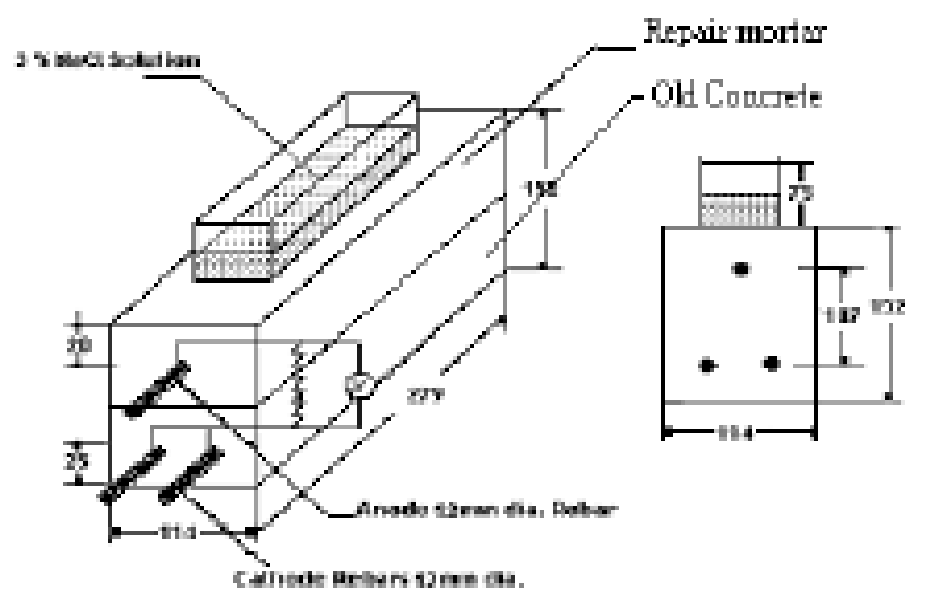

Figure 1. Schematic representation of macro cell corrosion test.

Before starting the experiment the top and bottom rebars were protected from the environment using some insulating material like araldite. Then the top and bottom rebars were electrically short-circuited using an $100 \Omega$ resistor. The galvanic current macro cell current flow between top and bottom bars was measured once in 8 days at the end of wet cycle as per procedure outlined in ASTM G 109-2001. One cycle consists of 4 days ponding in $3 \% \mathrm{NaCl}$ and 4 days drying in open atmosphere. At the end of the $15^{\text {th }}$ day measurements were made and the solution was completely drained using sponge. An 100-ohm resistor was placed between the top and bottom rebar and the potential difference $\mathrm{V}$ was measured. From this, the current was calculated as

$$
\mathrm{I}_{\mathrm{c}}=\mathrm{V} / 100
$$

Measurements were taken up to 180 days of exposure period. At the end of exposure period, the specimens were broken open and both top and bottom rebar 
were taken out for visual observation. The concrete sample near the anode rebar was collected and analyzed for alkalinity and chloride content. Visual observation was made on the top rebar and the extent of rusted area was observed.

\section{Gravimetric weight loss determination}

Half portion cast concrete cylinders were taken and the surface is roughened using sand blasting. Then the remaining portion is filled with different repair mortars by reinforcing with $12 \mathrm{~mm}$ diameter rebar of $70 \mathrm{~mm}$ long was embedded centrally in $50 \mathrm{~mm}$ diameter and $100 \mathrm{~mm}$ long cylinder specimen. The initial weights of the rebars were taken before embedment in the mortar. During casting $1 \%$ of chloride was added in the mortar mix in order to accelerate corrosion. After casting, the specimens were cured for 28 days. Then all the specimens were subjected to alternate wetting and drying in $3 \% \mathrm{NaCl}$ solution. The process is continued for 180 days. After 180 days the specimens were split open and visually examined for its rust initiation. Then all the rebars were cleaned in inhibited hydrochloric acid as per method prescribed in ASTM G1-1995 to remove the rust and the final weight of the rebar was measured. From the initial and final weights, loss in weight due to corrosion was determined.

\section{Results and discussion \\ Percentage of water absorption, volume of permeable voids and coefficient of water absorption}

Fig. 2 shows the \% of water absorption and the volume of permeable voids of different repair mortars. From the figure it is observed that system-II has the lowest water absorption of $7.72 \%$ and system- $\mathrm{V}$ has the highest water absorption of $10.44 \%$. When compared to control mortar, all the five systems have shown a lesser water absorption of $8-10.44 \%$. It is observed that the volume of permeable voids is found to be $13.6 \%$ for system-II and $15.4 \%$ for system-I, 15.6 $\%$ for system-III, $16.7 \%$ for system-IV and $19 \%$ for system-V, respectively. System -II shows $24 \%$ reduction in permeable voids when compared to control mortar of 1:3. When comparing all the modified mortar systems, system -II has shown lesser permeable voids which may be due to the fact that treated fly ash and micro silica particles are smaller than that of cement particles which caused denser packing of the cement matrix resulted in less permeable voids and less water absorption.

Fig. 3 shows the water absorption coefficient of different repair systems. System-II and system-IV are having a coefficient of water absorption of $3.47 \mathrm{x}$ $10^{-6} \mathrm{~mm}^{2} / \mathrm{sec}$. and $3.99 \times 10^{-6} \mathrm{~mm}^{2} / \mathrm{sec}$, respectively. When compared to control mortar, system-II has shown 1.97 times lesser water absorption coefficient. System-II is having treated fly ash of 5\% and micro silica 5\%. Both the materials are siliceous in nature, which combines with cement particles forming a denser structure called calcium silicate hydrate, which caused reduction in the water absorption coefficient. 


\section{Open circuit potential vs. time}

The embedded steel potentials measured periodically against a saturated calomel electrode (SCE) with time for different repair systems with chloride are shown in Fig. 4. From the figure it is observed that the systems have shown more than $275 \mathrm{mV}$ within 10 days of exposure. The same trend is maintained throughout the test period. Among the systems studied, systems I and II perform better than the other systems. From the above observation it is clearly understood that untreated fly ash added systems are showing inferior properties when compared to other systems. Activated fly ash and microsilica enhanced the corrosion resistance properties of embedded steel in concrete by pore reinforcement.

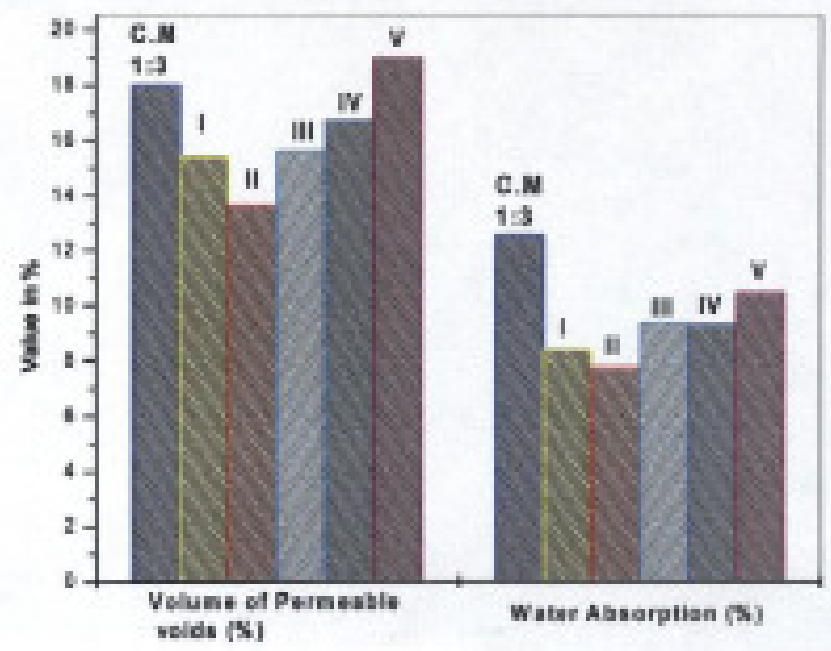

Figure 2. Volume of permeable voids and percentage water absorption.

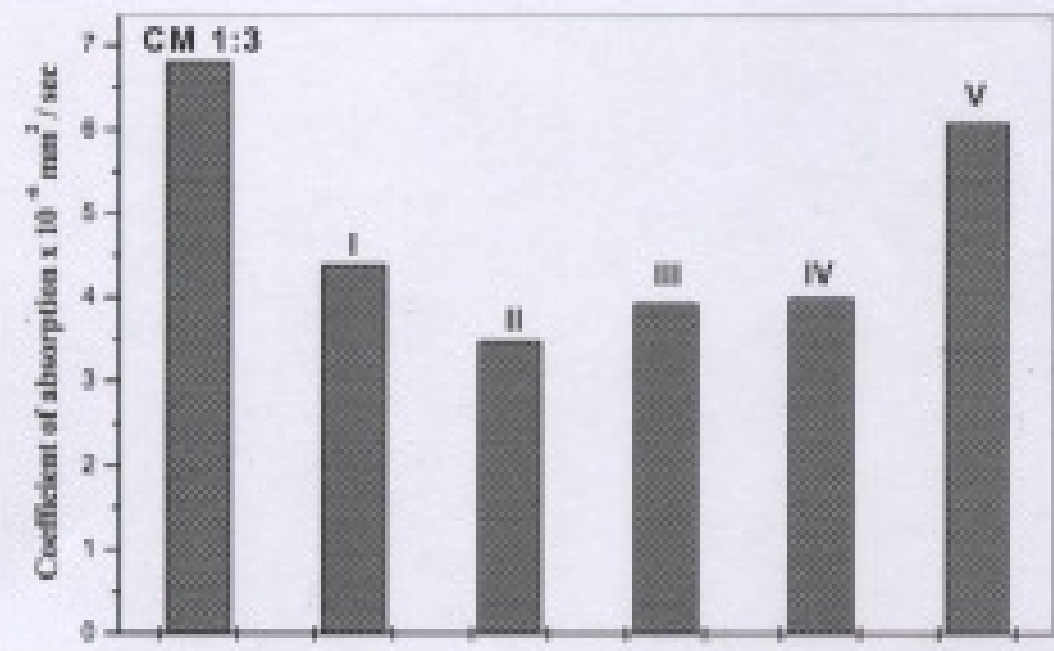

Figure 3. Coefficient of water absorption for different repair mortars. 


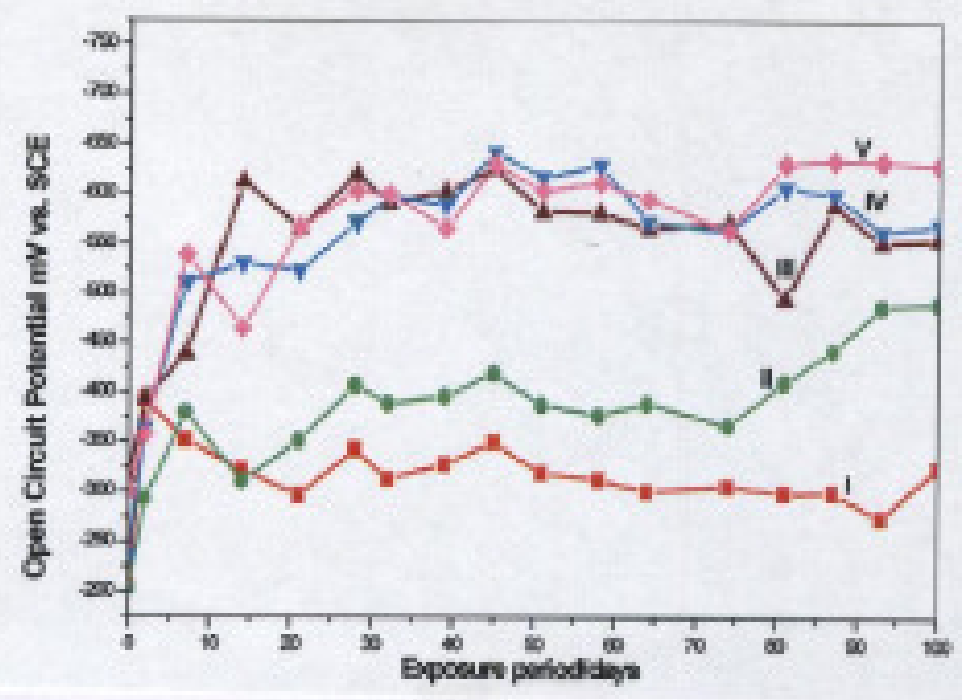

Figure 4. Open circuit potential vs. time behaviour of different repair mortars with $1 \%$ chloride.

\section{Impressed voltage test}

This technique is particularly used for comparing different characteristics of concrete. Impressed voltage test indirectly correlates the permeability of concrete with time by impressing a constant positive potential of $12 \mathrm{~V}$ between the anode (rebar embedded in concrete) and the cylindrical stainless steel cathode immersed in $5 \% \mathrm{NaCl}$ solution. The time taken for initial crack is recorded for different repair systems under different curing periods. The results are indicated in Fig. 5. From the figure it is observed that as the curing period increases the time to crack also increases. The time taken for initial crack of system II is 132 hrs after 90 days of curing. System I and system II have taken greater time to cracking when comparing to the other systems. From this study it is inferred that, micro silica and fly ash containing mortar reduced the permeability and thereby enhanced the corrosion resistance properties.

\section{Chloride permeability}

Fig. 6 indicates the coulombs obtained from rapid chloride permeation test results at 28 and 90 days curing for different modified repair mortars. The charge passed values get reduced against longer curing periods. After 90 days of curing systems I and II have 1168 and 833 coulombs, respectively. As per ASTM C 1202 systems having charge passed less than $1000 \mathrm{C}$ are rated as very low permeability, which indicates that system II has the lowest permeability when compared to the other systems. 


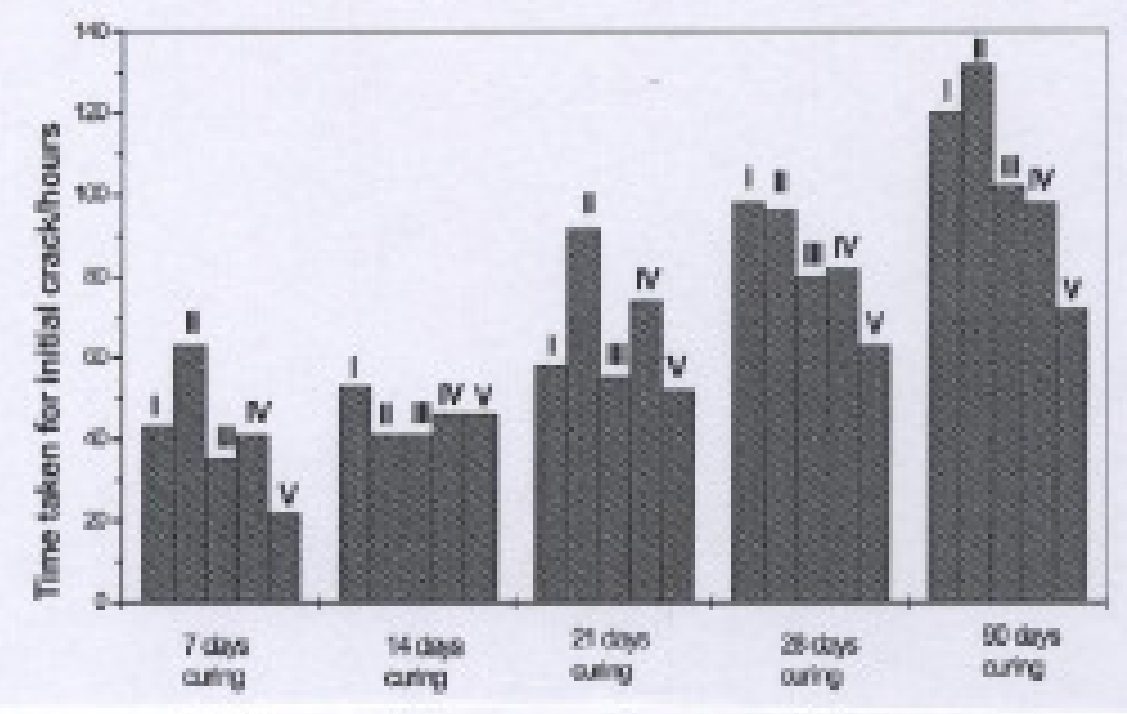

Figure 5. Results of impressed voltage test.

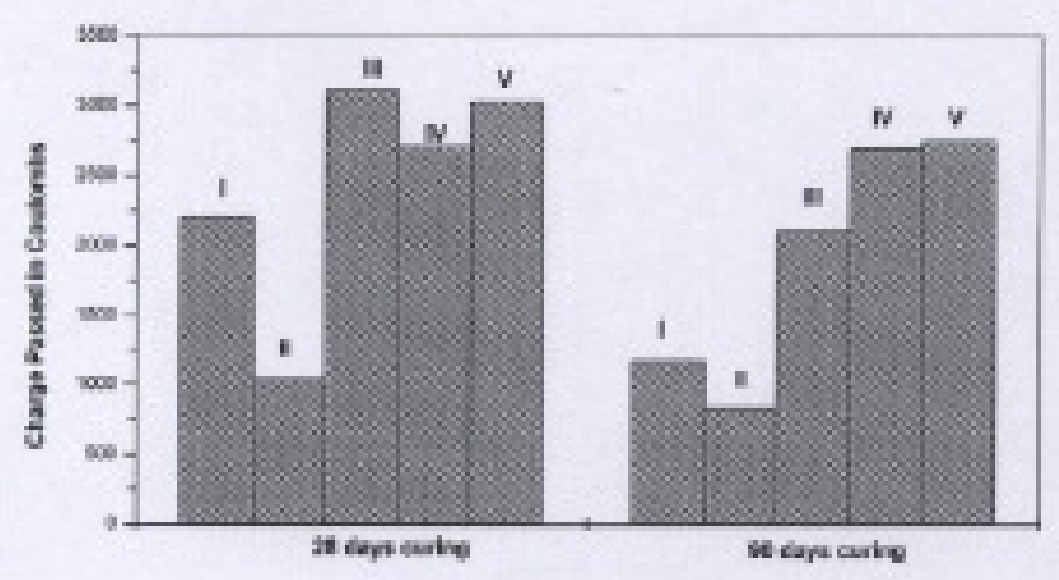

Figure 6. Results of rapid chloride permeability test.

\section{Free chloride analysis after 90 days ponding}

Fig. 7 shows the free chloride available at $20 \mathrm{~mm}$ and $40 \mathrm{~mm}$ depth after 90 days of ponding in $3 \% \mathrm{NaCl}$ solution. From the figure it is found that, at $20 \mathrm{~mm}$ depth the free chloride available is $1212 \mathrm{ppm}, 840 \mathrm{ppm}, 1410 \mathrm{ppm}, 1326 \mathrm{ppm}$ and 1476 ppm in systems I, II, III, IV, V, respectively. At $20 \mathrm{~mm}$ depth system II has the lowest free chloride content of $840 \mathrm{ppm}$ when compared to the other systems. When compared to $20 \mathrm{~mm}$ depth, the free chloride available at $40 \mathrm{~mm}$ depth is low.

At $20 \mathrm{~mm}$ depth the total chloride content is $0.072 \%, 0.05 \%, 0.083 \%, 0.078 \%$ and $0.087 \%$ for systems I, II, III, IV and V, respectively. Among the systems 
tested, system II has the lowest total chloride of $0.05 \%$. At $40 \mathrm{~mm}$ depth also system II and system I have the lowest free chloride content of 738 and $954 \mathrm{ppm}$ total chloride content of $0.044 \%$ and $0.056 \%$ which implies that, most of the free chlorides have bound with cement concrete and it has formed an impermeable concrete. It can be inferred that the reduced chloride ion penetration in modified cement mortar is mainly attributed by the pore filling effect of fly ash and micro silica by pozzolanic reaction. This reduction of chloride ion penetration causes the reduction of corrosion of the rebar.

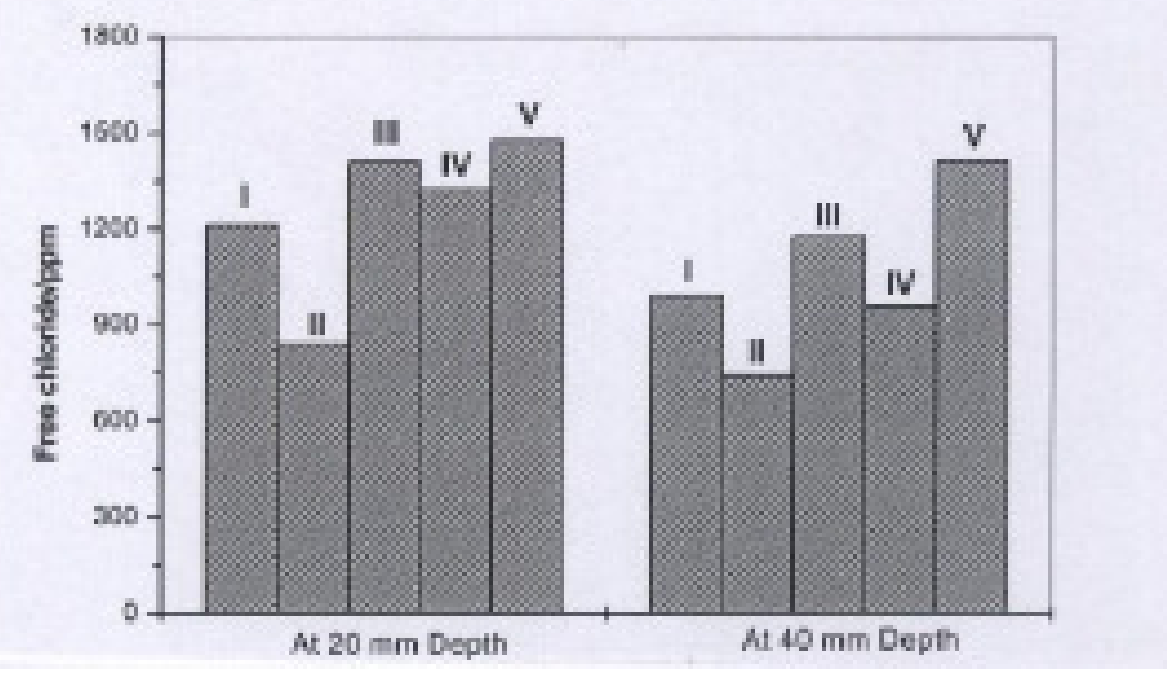

Figure 7. Free chloride at various depths after 90 days ponding test.

\section{Macro cell current vs. number of cycles}

Macro cell currents measured periodically with time for different systems are shown in Fig. 8. From the figure it is observed that systems I, II and III have shown a cathodic macro cell current of $229 \mu \mathrm{A}, 215 \mu \mathrm{A}$ and $110 \mu \mathrm{A}$ at the end of 100 days. Whereas the other two systems, namely systems IV and V, have shown an anodic macro cell current of $65 \mu \mathrm{A}$ and $80 \mu \mathrm{A}$, respectively. From the above observations, it is inferred that activated fly ash and micro silica containing mortars improved the corrosion resistant properties when compared to the other mortars. This is due to the fact that the filler effect and buffer effect minimized the permeation of chloride in inducing the corrosion of steel in embedded concrete.

\section{Visual observation}

Fig. 9 shows the \% area rusted for different types of mortars. From Fig. 9, it is found that systems I and II have very less area been corroded when compared to the other systems, which is in agreement with other methods' conclusions. 


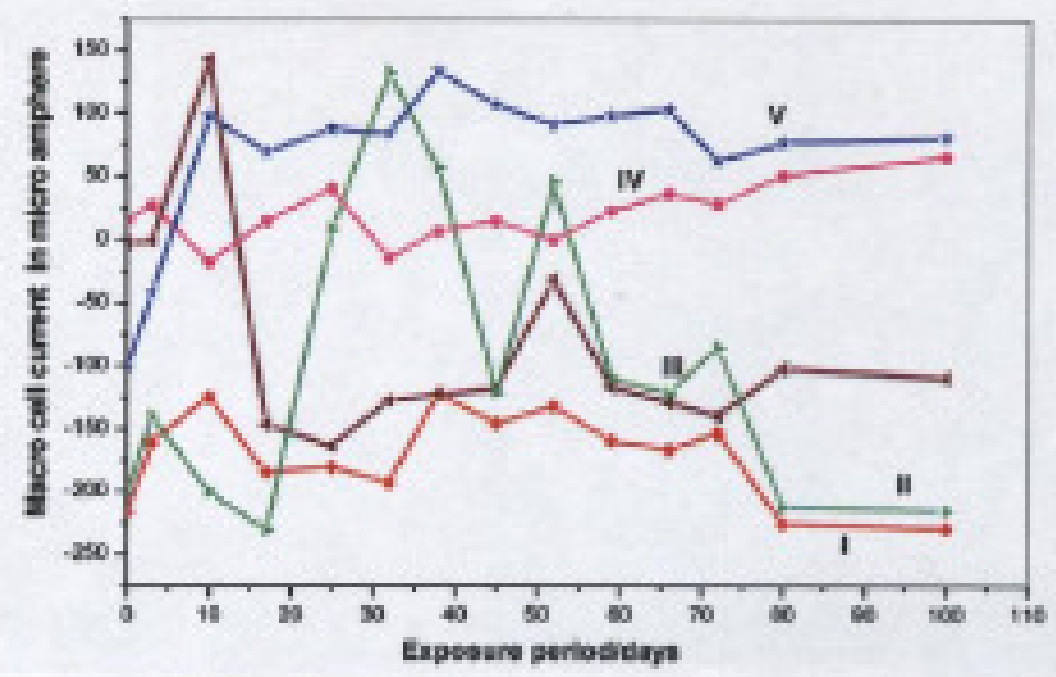

Figure 8. Macro cell current vs. time behaviour of different repair mortars.

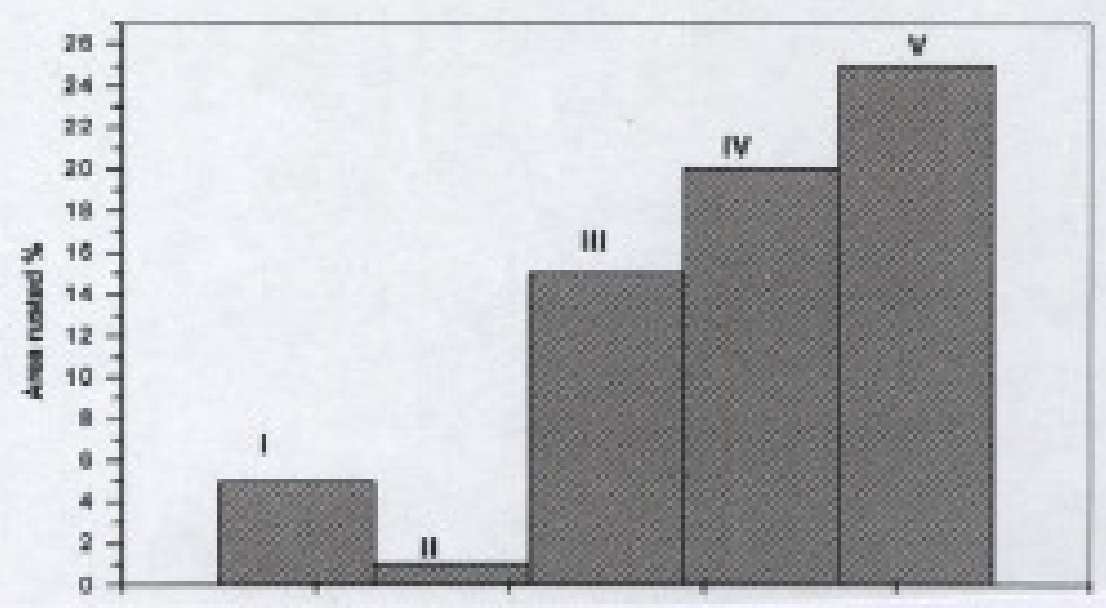

Figure 9. Visual observation in macro cell corrosion test.

\section{Corrosion rate from gravimetric weight loss}

Corrosion rate obtained from gravimetric weight loss method for $0 \%$ and $1 \%$ chloride contaminated mortars is shown in Fig. 10. In both $0 \%$ and $1 \%$ chloride admixed systems activated fly ash added (5\% and 7\%) and micro silica (5\%) containing systems performed well. This interesting observation is due to the fact that in the case of activated fly ash and micro silica the filler effect by micro particles and the secondary hydration reaction leading to the formation of calcium silicate hydrate $(\mathrm{CSH})$ gel formation leading to further decrease in corrosion rate. 


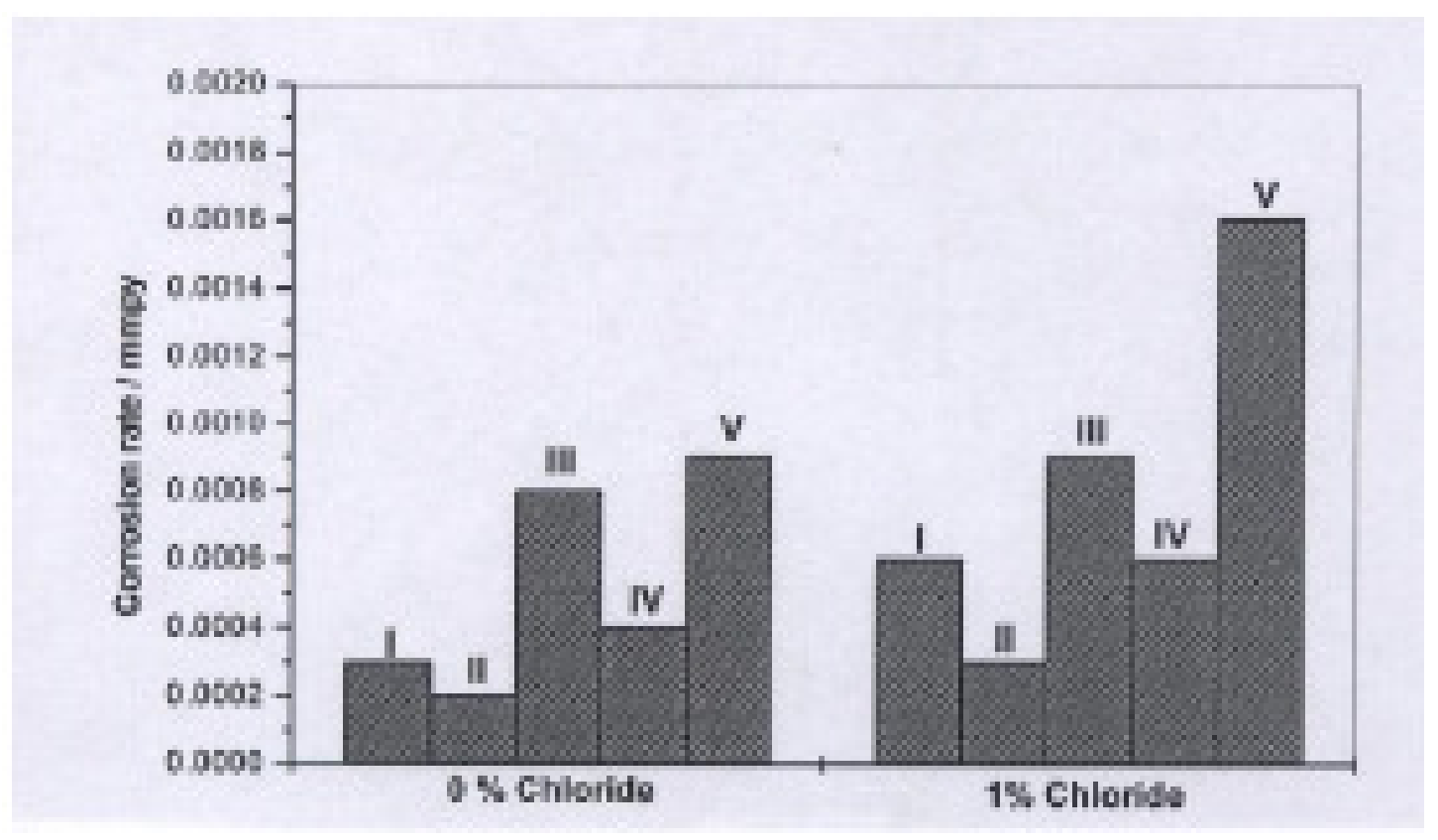

Figure 10. Corrosion rate obtained from gravimetric weight loss method.

\section{Conclusions}

The following conclusions can be drawn from the above investigations:

1. From the above investigations it is inferred that the formulated mortars are having good corrosion resistance properties.

2. Among the five formulated repair mortars, $5 \%$ treated fly ash with $5 \%$ micro silica (system II) is showing better performance than the other systems.

3. From the above investigations it is further inferred that the system II is suitable for structural application and other repair mortars are suitable for non-structural applications.

\section{Acknowledgments}

The authors thank The Director, CECRI, Karaikudi for kind permission to publish this paper. The authors also gratefully thankful to Center for Concrete Corea, Korea for the financial assistance.

\section{References}

1. F.M. Lea, The chemistry of cement and concrete, 3rd Ed, Great Britain: Edward Arnold; 1970, p. 553.

2. J.A. Gonzalez, A. Molina, E. Otero and W. Lopez, On the mechanism of steel corrosion in concrete: the role of oxygen diffusion, Mag. Concr. Res. 42-159 (1990) 23-27. 
3. F. Wenger, I. Galland, EIS study of the protective properties of repair products. In: Proceedings of the Eurocorr'96; Session I: Corrosion in concrete. Nice: 1996; P. I OR 8-1.

4. K. Byfors, Influence of silica fume and fly ash on chloride diffusion and $\mathrm{pH}$ values in cement paste, Cem. Concr. Res. 17 (1987) 115-130.

5. H.G. Wheat and Z. Eliezer, Some electrochemical aspects on corrosion of steel in concrete, Corrosion-NACE 41-11 (1985) 640-645.

6. N. Kouloumbi and G. Batis, Chloride corrosion of steel rebars in mortars with fly ash admixtures, Cem. Concr. Compos. 14 (1993) 199-207.

7. T. Miyagava, Durability design and repair of concrete structure: chloride corrosion of reinforcing steel and alkali-aggregate reaction, Mag. Concr. Res. 43-156 (1991) 155-170.

8. B. Sorensen, E. Maahn, Penetration rate of chloride in marine concrete structures, Publication 1, Nordic Concr. Res. (1982) 24.1-24.18.

9. C.H. Malami, G. Batis, N. Kouloumbi, V. Kaloidas, Influence of pozzolanic and hydraulic cement additions on carbonation and corrosion of reinforced mortar specimens, In: R.N. Swamy, Editor, Proceedings of the international conference on corrosion protection of steel in concrete, Sheffield, (1994), II p. 668-82.

10. N. Kouloumbi, G. Batis and C.H. Malami, The anticorrosive effect of fly ash, slag and a greek pozzolan in reinforced concrete, Cem. Concr. Compos. 16 (1994) 253-260.

11. C.H. Malami, V. Kaloidas, G. Batis and N. Kouloumbi, Carbonation and porosity of mortar specimens with pozzolanic and hydraulic cement admixtures, Cem. Concr. Res. 24-8 (1994) 1444-1454.

12. P.S. Mangat and M.C. Limbachiya, Repair material properties for effective structural application, Cem. Concr. Res. 27-4 (1997) 601-607.

13. G. Gudmudsson, H. Olafsson, Silica fume in concrete - 16 years of experience in Iceland, alkali-aggregate reaction in concrete. In: A. Shayan, Editor, Proceedings of the 10th International Conference, Melbourne, (1996), p. 462-69.

14. B. Lagerblad, P. Utkin, Silica granulates in concrete-dispersion and durability aspects, CBI Report 3.93. Swedish Cement and Concrete Research Institute, (1993) p. 44.

15. S.L. Marusin, L.B. Shotwell, Alkali-silica reaction in concrete caused by densified silica fume lumps - a case study, In: Proceedings of the Fifth CANMET/ACI International Conference on Fly Ash, Silica Fume, Slag and Natural Pozzolans in Concrete, Supplementary Volume, Milwaukee (1995) p. $45-59$.

16. M.N. Haque and O.A. Kayyali, Aspects of chloride ion determination in concrete, ACI Mater. J. 92-5 (1995) 532-541.

17. L.K. Aggarwal, P.C. Thapliyal, S.R. Karade, Properties of polymermodified mortars using epoxy and acrylic emulsions, Const. Build. Mat. 21 (2007) 379-383. 
18. F. Burak, S. Turkel, A. Yigit, Effects of steel fiber reinforcement on surface wear resistance of self-compacting repair mortars, Cem. Concr. Compos. 29-5 (2007) 391-396.

19. A.A. Nepomuceno, C. Andrade, Steel protection capacity of polymeric based cement mortars against chloride and carbonation attacks studied using electrochemical polarization resistance, Cem. Concr. Comp. 28-2 (2006) 716-721.

20. P. Sandberg, Studies of chloride binding in concrete exposed in a marine environment, Cem. Concr. Res. 29-4 (1999) 473-477. 